Editorial

\title{
Trends and Anti-Trends in Techno-Art Scholarship: The Legacy of the Arts "Machine" Special Issues
}

\author{
Juliette Bessette $1,2, * \oplus$, Frederic Fol Leymarie ${ }^{3, *}$ and Glenn W. Smith ${ }^{4, *}$ \\ 1 Centre André Chastel, Sorbonne Université, Galerie Colbert, 2 rue Vivienne, 75002 Paris, France \\ DFK Paris, 45 Rue des Petits-Champs, 75001 Paris, France \\ 3 Department of Computing, Goldsmiths College, University of London, London SE14 6NW, UK \\ 4 Space Machines Corporation, 671 Startouch Dr., Eugene, OR 97405, USA \\ * Correspondence: bessette.juliette@gmail.com (J.B.); FFL@gold.ac.uk (F.F.L.); \\ gsmith@space-machines.com (G.W.S.)
}

Received: 3 September 2019; Accepted: 11 September 2019; Published: 16 September 2019

\begin{abstract}
With the goal of casting a spotlight on the posture of the creative community at this crucial moment in human technological history, we present herein a thematic overview of the 23 articles published in the recent Arts Special Issues "The Machine as Art (in the 20th Century)" and "The Machine as Artist (for the 21st Century)". Surprisingly, several of the themes that had been suggested in our two introductory essays as representing shared and positive points of departure-in particular, (a) the visual arts as a longstanding touchstone of human culture, (b) the visual arts (with the example of John James Audubon) as having a unique ability to rally the public to the environmental cause, and (c) computer and robotic proficiency in the arts as leading to a friendlier artificial intelligence-received less than the expected amount of attention. Instead, it was another of the suggested themes (albeit also of a positive and forward-looking nature) around which our authors coalesced, as expressed in the following phrase: the "vast expansion of the creative sphere" which technology has made possible, or in other words, the idea that technology is not only providing new horizons for the professional artist but is also providing new avenues for the non-professional to discover his or her creative potential. In light, furthermore, of the marked enthusiasm for this theme, we suggest in our conclusion the need for a corresponding expansion of the venues available to both professional and non-professional techno-art practitioners.
\end{abstract}

Keywords: algorithm; artificial intelligence; computer-generated art; embodiment; emergent phenomenon; environmental crisis; GAN; generative adversarial network; machine art; neural network; techno-art

\section{Introduction}

The two Arts Special Issues "The Machine as Art (in the 20th Century)"1 and "The Machine as Artist (for the 21st Century)" 2 ran nearly simultaneously (with the "Machine as Artist", in fact, launching three months before "The Machine as Art", in April 2017, and with a final shared submissions deadline of December 2018); and they were coordinated, as well, in respect to both (1) their coverage areas-the former addressing that period starting roughly in 1950, during which the machine became a legitimate artistic medium (as in the works of Nicolas Schöffer and Jean Tinguely), and the latter addressing the contemporary period during which the modern machine, the computer, actually began

\footnotetext{
Available online: https://www.mdpi.com/journal/arts/special_issues/Machine_Art.

Available online: https://www.mdpi.com/journal/arts/special_issues/Machine_Artist.
} 
to participate in the creative process - and (2) their editorial approach, with the inaugural article in each Special Issue being an essay by the guest editor or editors setting out its scope and suggesting some potential themes as representing shared and positive points of departure.

Given, moreover, the interdisciplinary and speculative nature of the subject, a special effort was made to reach out beyond the art history community and to transcend the bounds of the typical research article. The results were most gratifying: the two Special Issues attracted a total of 23 articles, essays, and interviews by a variety of artists, art historians, engineers, and scientists, with many of them being notable individuals in their respective fields. ${ }^{3}$ As such, the topics that they chose to pursue throw a spotlight on the posture of the creative community at this crucial moment in human technological history, and so, there follows a straightforward thematic overview of the two Special Issues. It must be stressed, however, that this should in no way serve as a substitute for a reading of the individual articles themselves, each of which-and to whatever extent our subject themes have been dealt with—reflects its author's or authors' hard-won insights.

\section{Suggested Themes}

With the understanding that humankind finds itself in an unprecedented situation-facing a technological future which is at once beckoning and frightening but at the same time sustained for the

3 In alphabetical order by lead author.

Agüera y Arcas, B. Art in the Age of Machine Intelligence. Available online: http://www.mdpi.com/2076-0752/6/4/18.

Audry, S.; Ippolito, J. Can Artificial Intelligence Make Art without Artists? Ask the Viewer. Available online: https://www.mdpi.com/2076-0752/8/1/35.

Ballet, N. Survival Research Laboratories: A Dystopian Industrial Performance Art. Available online: https://www.mdpi. com/2076-0752/8/1/17.

Bessette, J. The Machine as Art (in the 20th Century): An Introduction. Available online: http://www.mdpi.com/20760752/7/1/4.

Broeckmann, A. The Machine as Artist as Myth. Available online: https://www.mdpi.com/2076-0752/8/1/25.

Carter, R. Waves to Waveforms: Performing the Thresholds of Sensors and Sense-Making in the Anthropocene. Available online: https://www.mdpi.com/2076-0752/7/4/70.

Edmonds, E. Algorithmic Art Machines. Available online: http://www.mdpi.com/2076-0752/7/1/3.

Edmonds, E. Communication Machines as Art. Available online: https://www.mdpi.com/2076-0752/8/1/22.

Gülzow, J.M.; Grayver, L.; Deussen, O. Self-Improving Robotic Brushstroke Replication. Available online: https://www.mdpi.com/2076-0752/7/4/84.

Hertzmann, A. Can Computers Create Art? Available online: http://www.mdpi.com/2076-0752/7/2/18.

LaViers, A.; Cuan, C.; Maguire, C.; Bradley, K.; Brooks Mata, K.; Nilles, A.; Vidrin, I.; Chakraborty, N.; Heimerdinger, M.; Huzaifa, U.; McNish, R.; Pakrasi, I.; Zurawski, A. Choreographic and Somatic Approaches for the Development of Expressive Robotic Systems. Available online: http://www.mdpi.com/2076-0752/7/2/11.

LaViers, A. Ideal Mechanization: Exploring the Machine Metaphor through Theory and Performance. Available online: https://www.mdpi.com/2076-0752/8/2/67.

Lijn, L. Accepting the Machine: A Response by Liliane Lijn to Three Questions from Arts. Available online: http://www.mdpi.com/2076-0752/7/2/21.

Lomas, A. On Hybrid Creativity. Available online: http://www.mdpi.com/2076-0752/7/3/25.

Moura, L. Robot Art: An Interview with Leonel Moura. Available online: http://www.mdpi.com/2076-0752/7/3/28.

Mazzone, M.; Elgammal, A. Art, Creativity, and the Potential of Artificial Intelligence. Available online: https://www.mdpi.com/2076-0752/8/1/26.

Nechvatal, J. Before and Beyond the Bachelor Machine. Available online: https://www.mdpi.com/2076-0752/7/4/67.

Rolez, A. The Mechanical Art of Laughter. Available online: https:/www.mdpi.com/2076-0752/8/1/2.

Simmons, S. Drawing in the Digital Age: Observations and Implications for Education. Available online: https://www.mdpi.com/2076-0752/8/1/33.

Smith, G.W.; Leymarie, F.F. The Machine as Artist: An Introduction. Available online: http://www.mdpi.com/2076-0752/6/2/5.

Smith, G. W. An Interview with Frieder Nake. Available online: https://www.mdpi.com/2076-0752/8/2/69.

Still, A.; d'Inverno, M. Can Machines Be Artists? A Deweyan Response in Theory and Practice. Available online: https://www.mdpi.com/2076-0752/8/1/36.

Tosa, N.; Pang, Y.; Yang, Q.; Nakatsu, R. Pursuit and Expression of Japanese Beauty Using Technology. Available online: https://www.mdpi.com/2076-0752/8/1/38. 
foreseeable part of that future by planetary ecosystems under grave threat ${ }^{4}$ - it seemed advisable to us as editors to go beyond a mere posing of the question, "Where do we stand, artistically and otherwise, vis-à-vis our machines?", by suggesting some themes in our respective introductory essays which would convey not only the gravity of the situation but also the possibility of positive action:

- The visual arts—and, by implication, the performing arts—as longstanding touchstones of human culture and thus of inestimable value as we face a flood tide of technology;

- The visual arts, amidst this same flood of technology, as having a unique ability to rally the public to the environmental cause;

- Computer and robotic proficiency in the arts as leading to a friendlier technology in general and, in particular, to a friendlier artificial intelligence, i.e., a technology informed by the cultural and human-centric approach of artists;

- Technology as fostering a "vast expansion of the creative sphere", i.e., as providing new creative opportunities for both professional and non-professional artists.

Surprisingly, the first three of these themes (Table 1$)^{5}$ received less than the expected amount of attention from our authors; and indeed, we as editors cannot avoid expressing some disappointment at their relative neglect. As society searches for some footing amidst the onslaught of technology, for example, one might suppose that the visual arts, which have existed in recognizable form for some 30 centuries (Gombrich 1996), would receive more notice on that account. Similarly, and amidst this same flood of technology, an apparent reluctance to embrace the utility of the visual arts in celebrating the natural world is likewise a mystery, although we might have done well to have used Ansel Adams as an example (Figure 1) - he of Sierra Club fame-in addition to John James Audubon. Even more puzzling was the following question: why is there not more interest in the idea that learning how to build aesthetic pathways into software (e.g., a sense of harmony and balance, attention to detail, and a concern also for the "big picture") is also a vital step in the creation of a human-friendly artificial intelligence?

Table 1. Major themes of the two Arts Special Issues "The Machine as Art (in the 20th Century)" and

"The Machine as Artist (for the 21st Century)".

\begin{tabular}{|c|c|c|}
\hline Theme & \multicolumn{2}{|c|}{ Number of Articles } \\
\hline Human/machine partnership in art production & 14 & $x \times \times \times \times \times \times \times \times \times \times \times \times x$ \\
\hline Artificial intelligence as a significant factor & 11 & $\times \times \times \times \times \times \times \times \times \times \times$ \\
\hline Aesthetics as leading to a friendlier technology & 8 & $\times \times \times \times \times \times \times \times$ \\
\hline Algorithmization/technification of society as a concern & 8 & $\times \times \times \times \times \times \times \times$ \\
\hline Emergent phenomenon as a significant factor & 5 & $x \times x \times x$ \\
\hline Embodied experience as critical to our understanding & 5 & $\times \times \times \times \times$ \\
\hline Machine as medium (in traditional sense of the word) & 4 & $\times \times \times \times$ \\
\hline Machine art as healthy challenge to human imagination & 4 & $\times \times \times \times$ \\
\hline Machine as producing legitimate art & 4 & $\times \times \times \times$ \\
\hline
\end{tabular}

Yet, such concerns are all but swept away in considering the outpouring of thought and enthusiasm given by our authors to the theme expressed in the following phrase: the "vast expansion of the creative

4 As we are reminded by Teilhard de Chardin (1969), we still have "feet of clay".

5 The complete "Machines Special Issues Thematic Analysis" on which Table 1 is based and consisting of an article-specific breakdown of addressed themes, has been made available in the Supplementary Materials; however, it must be emphasized again that this beakdown was done on a discursive rather then rigorously logical basis, and that, in any event, all such systems of categorization are inherently problematical. 
sphere" which technology has made possible. ${ }^{6}$ As set forth, for example, in a pair of definitive essays by two of our most prominent contributors, the technology of photography was initially seen as a threat to the visual arts; and indeed, it did have a negative impact on portraiture and landscape painting. In the long run, however, the scope of the visual arts was in fact enlarged by this new technology, and in more or less obvious ways: with respect to the latter, the challenge posed to representational painting pushed artists in new directions and thus helped give rise to abstraction and expressionism; and in a more obvious manner, photography itself is now recognized as one of the fine arts, and in which capacity it has allowed a huge new cadre of individuals to discover themselves as artists, at both the professional-e.g., the aforementioned Ansel Adams—and amateur levels. This process, moreover, can be expected to repeat itself, and here, we refer in particular to neural net-based image generation: another of our flagship essays, for example, describes a generative adversarial network (GAN) system which might allow a new generation of individuals to discover their creative potential by empowering them to curate image collections beyond our current power of imagining.

In truth, such was the enthusiasm accorded this theme-with no less than 20 of our 23 articles touching upon it in some fashion-that, in retrospect, it must be admitted that this was a subject that our authors were ready to take up even in advance of our introductory essays. We are obliged, in turn, to inquire as to what deeper intuitions on their part might be thereby represented; and an answer readily presents itself: while perhaps ignoring a technologically-mediated environmental crisis, have not our authors chosen to weigh in on a parallel crisis, namely, the challenge posed by the machine to the human psyche? In choosing to emphasize the positive side of the equation-i.e., the idea that technology could help each of us reach our full creative potential (or, to use a term employed by author Blaise Agüera y Arcas, the idea that technology will at last "democratize" artistic production, such that it is no longer the province of an elite few (Agüera y Arcas 2017)) - have they not also implicitly acknowledged its opposite (and this is perhaps something to keep in mind as we contemplate the unrest being experienced in some of our industrialized Western countries): the fear felt by many that they will be increasingly in competition with computers and robots for their respective positions within society?

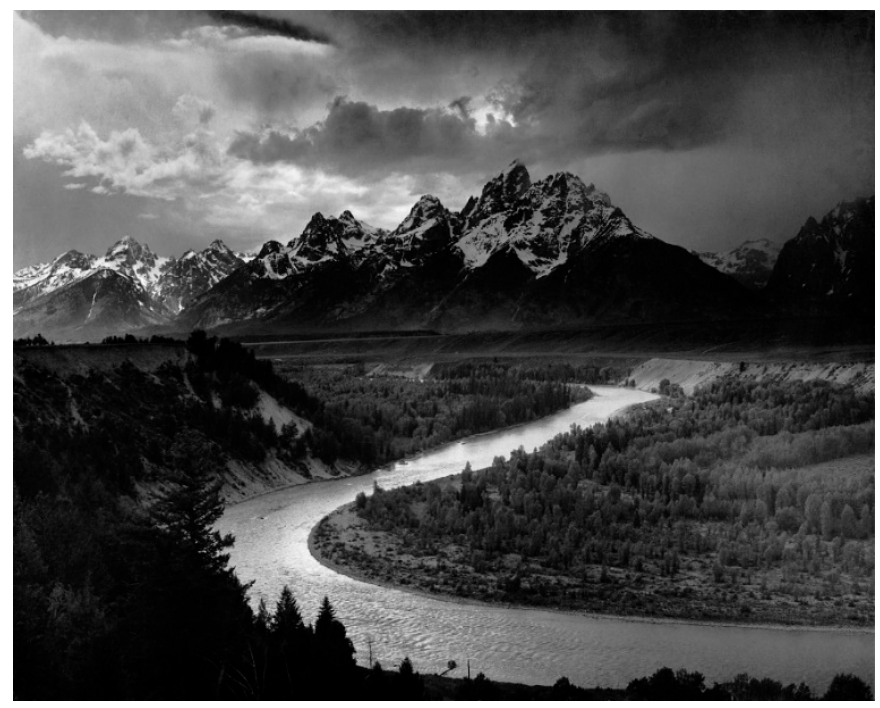

Figure 1. The Tetons and the Snake River, by Ansel Adams, 1942 (Public domain image).

6 Or—in the original French—“une large ouverture de la sphère créative” (Bessette 2018). 


\section{Other Themes}

Returning now to Table 1 (and with the understanding that this is a discursive rather than a logically rigorous categorization), it can be seen that there are several other themes that gained a significant degree of traction among our authors, as elucidated in several noteworthy articles:

- The idea that human-computer partnerships can yield impressive artistic results (this is a subset of the "expansion of the creative sphere");

- The algorithm as a significant factor in current techno-art production, it being understood that, from a purely technical standpoint, this is what we are really talking about in most discussions involving the computer and/or artificial intelligence;

- Artificial intelligence as a significant factor in current techno-art production (and which, for the purposes of these Special Issues, might have been better referred to as "machine intelligence");

- The algorithimization/technification—or, to put it more bluntly, the de-humanization—of society as a concern;

- Emergent phenomenon-i.e., the ability of relatively simple systems to exhibit relatively complex behaviors, as with robot swarms or the current crop of AI algorithms-as another significant factor in current techno-art production;

- Embodied experience as critical to our understanding, i.e., the idea that the efficient organism —or robot—is best modeled as a system in which sensation, computation, and action are treated as a continuum rather than according to a Cartesian body-mind duality, and hence the utility of bringing the embodied arts such as dance into the picture when designing complex systems;

- The machine as a medium in the traditional sense of the word;

- Machine art as posing a healthy challenge to the human imagination (this is also a subset of the "expansion of the creative sphere");

- The machine as able to produce legitimate art.

The last of these, in that it represents the theoretical crux of our two Special Issues, demands some additional commentary; and in fact, at least two of our contributions describe systems for which the claim is made that they are capable, and on an essentially independent basis, of producing original and not-insignificant works of art. These, to be sure, are in both cases abstract paintings—on the one hand, produced by micro-robot swarms via the aforementioned (and quite real) phenomenon of emergence and, on the other, by the similarly aforementioned GAN system, as a function of it having pre-digested multiple works by human abstract artists; and the results-to the eye, at least (i.e., without rehearsing the several technical and philosophical discussions that our Special Issues have been fortunate enough to have attracted)—are truly impressive.

\section{Conclusions}

We would like to dedicate our conclusion to a single topic, as justified by its gravity: if we accept the idea that technology will continue to "expand the creative sphere" - and that this is an antidote to its disruptive tendencies-then it would seem to behoove us to advocate for the parallel expansion of opportunities for artists, both professional and non-professional, to exhibit works of techno-art. Or, more generally, it would seem to behoove us to advocate for much more exposure in the world art scene for the emerging category of what we could call "machine art": art practices that clearly and deeply engage with machines, including the design and use of software by and for human artists. If we as a society were to follow through with such a program, we might not only discover that the healing influence of artistic creation has in fact been significantly democratized but also that our own machines, in their continued evolution, have been given the opportunity to become friendlier and more human-aware entities. 
Supplementary Materials: Machines Special Issues Thematic Analysis (http://www.mdpi.com/2076-0752/8/3/120/s1). Acknowledgments: The authors would like to express our deep appreciation to all of our contributors.

Conflicts of Interest: The authors declare no conflict of interest.

\section{References}

Agüera y Arcas, Blaise. 2017. Art in the Age of Machine Intelligence. Arts 6: 18. [CrossRef] Bessette, Juliette. 2018. The Machine as Art (in the 20th Century): An Introduction. Arts 7: 4. [CrossRef] de Chardin, Pierre Teilhard. 1969. The Future of Man. New York: Harper \& Row, p. 242.

Gombrich, Ernst. 1996. The Miracle at Chauvet. The New York Review of Books, November 14.

(C) 2019 by the authors. Licensee MDPI, Basel, Switzerland. This article is an open access article distributed under the terms and conditions of the Creative Commons Attribution (CC BY) license (http://creativecommons.org/licenses/by/4.0/). 